\title{
Australia's Gambling Epidemic: The Role of Neighbourhood Ethnic Diversity
}

\author{
Sefa Awaworyi Churchill ${ }^{1}$ (D) . Lisa Farrell ${ }^{1}$ \\ Published online: 5 June 2019 \\ (c) Springer Science+Business Media, LLC, part of Springer Nature 2019
}

\begin{abstract}
Gambling is a popular leisure activity but also a significant public health issue in Australia. The severity of gambling in Australia is characterised by unprecedented gambling expenditures and losses representing the highest gambling rates in the world, which has led to renewed interests in understanding the factors influencing gambling behaviours. We contribute to the debate on the determinants of gambling by providing the first study that examines the impact of ethnic diversity on gambling. Using data from the Household, Income and Labour Dynamics in Australia survey, we find that ethnic diversity is positively associated with gambling. This result is robust to alternative estimation approaches, alternative ways of measuring ethnic diversity and irrespective of whether gambling is measured using the Problem Gambling Severity Index, gambling expenditures or number of gambling activities. Our results also suggest stronger effects of ethnic diversity for problem gamblers compared to gamblers in other risk categories. These results support the need for policies that promote social capital in diverse communities to reduce the risks of social isolation, which is an important motivator of gambling behaviour.
\end{abstract}

Keywords Ethnic diversity · Gambling · PGSI · Australia

\section{Introduction}

Gambling is widely viewed as a legitimate and socially acceptable leisure activity (Calado and Griffiths 2016; Stucki and Rihs-Middel 2007). However, gambling has also been identified as being addictive and problematic with severe negative consequences, to the extent

This paper uses unit record data from the Household, Income and Labour Dynamics in Australia (HILDA) Survey. The HILDA Project was initiated and is funded by the Australian Government Department of Social Services (DSS) and is managed by the Melbourne Institute of Applied Economic and Social Research (Melbourne Institute). The findings and views reported in this paper, however, are those of the authors and should not be attributed to either DSS or the Melbourne Institute.

Sefa Awaworyi Churchill

sefa.churchill@rmit.edu.au

Lisa Farrell

lisa.farrell@rmit.edu.au

1 School of Economics, Finance and Marketing, RMIT University, Melbourne, VIC 3000, Australia 
that some individuals experience harm as a result of their gambling behaviour (Currie et al. 2006; Langham et al. 2016; Splevins et al. 2010). Gambling addiction was initially defined as an impulse control disorder in the Diagnostics and Statistical Manual of Mental Disorders, DSM-III (American Psychiatric Association (APA) 1980) and reclassified in DSM-V (APA 2013) as a behavioural addiction (for a discussion see Hasin et al. 2013). Further, gambling addiction (pathological gambling) has been recognised as one of the most difficult disorders to treat (Volberg 1996), with evidence suggesting that it has become a problem for many countries across the globe. A recent systematic review found that the prevalence of problem gambling across the world was up to $5.8 \%$ with varying estimates across different countries (Calado and Griffiths 2016). The associated negative social and health consequences of problem gambling have made gambling a major public policy agenda in many developed countries, and the legalisation and licencing of gambling venues have therefore been considered public health concerns in countries such as the United States, Australia and the United Kingdom (Korn et al. 2003; Levens et al. 2005; Shaffer and Korn 2002).

Blaszczynski and Nower (2002) introduce a pathway model of problem gambling where three groups were identified. Group 1 are the 'Behavioural Conditioned', whose pathway to problem gambling is characterised by environmental factors such as the social context and a family history of gambling, among others. Group 2 are the 'Emotionally Vulnerable', whose pathway is characterised by mood disorders such as depression and anxiety, and Group 3, 'Antisocial Impulsivists', are characterised by various personality disorders. In this paper, we contribute to understanding the factors that play a role in the Behavioural Conditioned pathway, with a focus on the impact of local area/neighbourhood effects. We contribute to the literature by examining the impact of ethnic diversity on gambling. Alongside the increasing prevalence of gambling, local communities around the world are increasingly becoming diverse, and the implications of this diversity have been the focus of a growing body of research (Akay et al. 2017; Dincer 2011; Easterly and Levine 1997). We argue that the level of ethnic diversity within a community is likely to influence gambling behaviour given different cultures have different attitudes to gambling (Raylu and Oei 2004).

Conceptually, ethnic diversity could be negatively or positively associated with gambling, and thus understanding the relationship between ethnic diversity and gambling is an empirical task. Consistent with a negative association, ethnic diversity has been shown to influence social capital, an important factor that plays a role in gambling decisions. Existing research has demonstrated a negative association between ethnic diversity and social capital (Awaworyi Churchill 2017; Dincer 2011; Dinesen and Sønderskov 2015). Social capital plays an important role in shaping the social environment, which may either promote or discourage gambling. For instance, with lower social capital that engenders social isolation, individuals might find ways to cope with isolation and this could drive them towards gambling and other addictive behaviours (McQuade and Gill 2012; Thomas et al. 2009). Further, people may gamble more when they do so with acquaintances or play in groups (Griffiths and Barnes 2008; Rogers and Webley 2001). Thus, peer effects linked with social capital play significant roles in influencing gambling behaviour (Bursztyn et al. 2014; Rogers 1998).

The increase in problem gambling is often linked to the supply of opportunities to gamble. For example, Marshall (2005) shows that at the local area level, gambling behaviours can be linked to the availability of electronic gaming machines, which is known to be correlated with local area deprivation (Wardle et al. 2014). Higher levels of ethnic diversity have been shown to hinder collective action (see, e.g., Glennerster et al. 2013). Thus, even 
if gambling addiction is found to negatively influence wellbeing, the lack of collaboration associated with higher diversity could hinder collective action (from non-gamblers and policymakers) aimed at efforts to reduce the supply of gaming machines within a community. On the other hand, ethnic and cultural diversity is positively associated with higher wages and productivity through its effects on innovation (Hewlett et al. 2013; Ottaviano and Peri 2006; Trax et al. 2015). Thus, with higher wages resulting from cultural and ethnic diversity, the socio-economic gap narrows and financial challenges are less likely to drive people towards gambling, given that gambling is known to be higher among lower socio-economic groups (Brown et al. 1992; Clotfelter and Cook 1999; van der Maas 2016).

Our study is based in Australia, which makes for an important case study given that it is one of the most diverse countries in the world. The most recent Australian census shows that $26 \%$ of the Australian population were born overseas while about $50 \%$ of the population were either born overseas or have at least one parent who was born overseas (Australian Bureau of Statistics 2017). More importantly, gambling is a popular activity and a significant public health issue in Australia. Recent surveys show annual gambling participation prevalence of about $64 \%$ and up to $74 \%$ for some Australian states and territories (Davidson et al. 2016; Dowling et al. 2016; Stevens et al. 2015). The latest statistics on gambling in Australia released by the Queensland Government Statistician's Office also demonstrate that between 2016 and 2017, Australians gambled AUD \$209 billion and lost AUD \$24 billion, which represents a per capita loss of approximately AUD \$1300. These figures suggest that Australia has the highest gambling rates in the world. The severity of gambling in Australia is even more pronounced when compared to other countries that are well-known for gambling. For instance, gambling losses per adult in Australia are more than double those in the United States (US) and other Western countries (Queensland Government Statistician's Office 2018).

We use data from the Household, Income and Labour Dynamics in Australia (HILDA) survey. Until recently, Australia has had limited data from which to research and hence understand the patterns of gambling behaviours within a population-based sample. Crosssectional surveys have been conducted within Australia (see, e.g., the discussion by the Productivity Commission 2010), but the trade-off in obtaining detailed information on gambling is that only limited socioeconomic data can be collected due to survey length and cost considerations. Other knowledge is extracted from data using clinical samples that, by definition, do not allow us to understand the consumption patterns of sub-clinical populations. The introduction of detailed gambling data (in 2015), in wave 15 of the HILDA survey, offers a unique opportunity to explore gambling expenditure in a rich, nationally representative household-level data set. Investigating population-based samples aids our understanding of how society, as a whole, is impacted by the increasing presence of gambling products in our communities and our daily lives.

Using the HILDA survey data, we measure ethnic diversity at the neighbourhood level, and focus on the Problem Gambling Severity Index (PGSI) as our main measure of gambling risk. We contribute to literature on the determinants of gambling (Baron and Dickerson 1999; Gainsbury et al. 2014; Savolainen et al. 2018; Subramaniam et al. 2015), and the implications of ethnic diversity (Akay et al. 2017; Awaworyi Churchill 2017; Dincer 2011; Easterly and Levine 1997). Our study also contributes to a small literature that examines ethnic differences in gambling rates (Chhabra 2007; Raylu and Oei 2004; Walker et al. 2006). For instance, in the US, research has shown that Hispanic, Asian and Black adolescents spend significantly more on gambling than White adolescents (Volberg et al. 2008), while in Australia, studies have found higher levels of gambling among Chinese residents than other residents (Oei and Raylu 2010). Our study differs from these studies in that we 
do not focus on variations in gambling rates between ethnic groups. Accordingly, we present the first study examining how the level of ethnic diversity in a community influences gambling.

The next section presents an overview of the data and variables used in this study. Third section describes the empirical methods and fourth section presents the results. Fifth section concludes the study.

\section{Data and Variables}

Data used in this study are drawn from the HILDA survey. HILDA is a nationally representative longitudinal survey modelled on the British Household Panel Survey (now known as the Understanding Society study) and the US Panel Study of Income Dynamics. The survey commenced in 2001 with approximately 19,900 adults and children in 7682 households. The survey collects information on household demographics, social and economic characteristics, and a wide range of personal and attitudinal questions collected via a self-completed questionnaire (Watson and Wooden 2012). As noted, wave 15 was the first time the gambling module was included in the HILDA survey, and thus, our study focuses on waves 1 to 15 of the HILDA survey.

\section{Measuring Gambling Behaviour}

The gambling module in wave 15 of the HILDA survey consists of components relating to participation in gambling activities, expenditures on gambling and gambling problems. Consistent with the gambling literature (Awaworyi Churchill and Farrell 2018; Korman et al. 2008; Raisamo et al. 2014), our main measures of gambling behaviour are based on the PGSI measure of gambling behaviours (Ferris and Wynne 2001). The PGSI was designed to be an effective instrument for accessing problem gambling severity in population-based samples and has been extensively tested and validated (Currie et al. 2013; Holtgraves 2008; Orford et al. 2010). The PGSI is based on a nine-item questionnaire that captures adverse consequences of gambling experienced and problematic gambling behaviour in the past 12 months. The nine items (shown in Table 9) are rated on a four-point scale, where 0 represents 'never' and 3 represents 'almost always'. The PGSI is a sum of responses from the nine-item questionnaire and thus scores range from 0 to 27 with higher scores representing greater gambling problems. We use the PGSI scores as our first measure of gambling behaviour.

The second measure reflects problem gambling risk status based on risk thresholds. The existing literature assigns risk categories to gamblers based on their PGSI scores. This allows us to group survey respondents with similar risks of developing harmful gambling behaviours from low risk to high risk. Four risk groupings are identified: (1) nonproblem gamblers; (2) low-risk gamblers; (3) moderate-risk gamblers; and (4) problem gamblers. Non-problem gamblers are identified as those who did not experience adverse consequences of gambling or engage in any problematic gambling behaviour in the past 12 months, and thus have a PGSI score of 0. Low-risk gamblers are those with PGSI scores of 1-2, moderate-risk gamblers are those with scores 3-7, and problem gamblers are those with PGSI scores of 8 or above. From this transformation of the continuous PGSI into risk categories, a four-point ordinal scale is created that captures the various risk spectrums such that 1 represents non-problem gamblers 2 represents low-risk gamblers, 3 represents 
moderate-risk gamblers and 4 represents problem gamblers. To examine the effects of social capital on the various risk spectrums, we also use four dummy variables reflecting respondents in each gambling risk spectrum as one of our model specifications.

\section{Measuring Ethnic Diversity}

Our main measure of ethnic diversity is based on the fractionalisation index, which is the most commonly used measures of ethnic diversity in the literature, although in the robustness check, we also use the polarisation index. The ethnic polarisation index is argued to be an effective measure of ethnic diversity that takes into account the conflict dimension of diversity (Montalvo and Reynal-Querol 2005).

The index of fractionalisation is calculated using the Herfindahl formula (Greenberg 1956) as follows:

$$
F R A C_{j}=1-\sum_{i=1}^{i} n_{i j}^{2}
$$

where FRAC is the index of fractionalisation and $n_{i j}$ is the population share of ethnic group $i$ in neighbourhood (postcode) $j$. This index captures the probability that two randomly selected individuals in a given Australian neighbourhood (postcode) belong to different ethnic groups.

We define ethnic groups based on country of birth of respondent's father. The HILDA survey presents information that allows ethnic groups to be classified either based on country of birth or parent's (father's) country of birth. Studies such as Leigh (2006), which also generate indices of ethnic diversity for Australian neighbourhoods, define ethnic groups using respondents' country of birth. Our use of the country of birth of respondent's father has the advantage of capturing 'ethnicities' of respondents who were born to first generation migrants in Australia, although in sensitivity checks, we find that the nature of our results are not altered if we define ethnic groups using respondents' country of birth. Overall, we generate indices of ethnic diversity for 1850 neighbourhoods (postcodes). An alternative approach will be to use information from the Australian census to generate indices of diversity at the postcode level, which can then be merged with the HILDA dataset. However, this information is not available to us.

Using the same classification of ethnic groups use for the calculation of ethnic fractionalisation, we also generate indices of polarisation using the approach in Montalvo and Reynal-Querol (2005) as follows:

$$
P O L=1-\sum_{i=1}^{i}\left(\frac{0.5-n_{i j}}{0.5}\right)^{2} \cdot n_{i j}
$$

$P O L$ is the index of polarisation and measures the distance of any distribution of ethnic groups from the situation that leads to the maximum conflict. $n_{i j}$ is the share of ethnic group $i$ in neighbourhood (postcode) $j$. Distances are assumed to be equal among all groups, and thus the degree of ethnic polarisation only depends on the size of ethnic groups. The closer the distribution of ethnic groups in a locality, the higher the index of polarisation.

We take advantage of the longitudinal nature of the HILDA survey, and use measures of ethnic diversity that are averaged across the first 14 waves of HILDA. This approach presents the dual benefit of addressing potential measurement error issues of using ethnic 
diversity measures from just a single wave, while capturing persistence in ethnic diversity that is accumulated over time. We are not concerned with HILDA waves that come after the gambling module because it is not plausible that ethnic diversity in the future would influence gambling activity in the past.

\section{Covariates}

We control for a set of control variables consistent with the literature (Delfabbro and Thrupp 2003; Gainsbury et al. 2014; Layton and Worthington 1999; Tan et al. 2010) including gender, age, number of dependants, marital status, income (in log), employment status, educational status, disability status, drinking status, nationality, and residence location (dummy variable for respondents living in urban locations). In robustness checks, we also include additional control variables including personality traits and measures of financial risk averseness. Table 10 presents a description and summary statistics of variables.

In a potential channel analysis, we also use data on social capital drawn from the HILDA survey. Our measure of social capital reflects the dimensions of social cohesion and networking based on a six-item questionnaire. The six items, shown in Table 11 together with the associated response scales, measure how respondents strongly agree or disagree with sentiments about their neighbours and neighbourhood. The measure of social capital is the average of responses from the six items, with higher and lower scores representing higher and lower social capital, respectively.

\section{Data for Instrumental Variable}

As discussed in further detail in the next section, we use measures of ethnic diversity, at the state level using information from the 1991 Australian population census, as instrument in two-stage least square regressions to deal with potential issues of endogeneity. Apart from this data which is drawn from the Australian Bureau of Statistics (ABS) databases, all other variables are taken or derived from the HILDA survey.

\section{Econometric Specification and Methods}

Our baseline estimates are based on the following equation:

$$
G B_{i}=\alpha+\beta_{1} E T H_{i}+\sum_{n} \beta_{n} X_{n, i}+\varepsilon_{i}
$$

where $G B$ is the measure of gambling behaviour of individual $i$ while $E T H$ is the measure of ethnic diversity in their neighbourhood. $X$ is a set of control variables $\varepsilon$ is the error term. For our baseline results, we use ordinary least squares (OLS).

OLS results may be biased in the presence of endogeneity. Endogeneity may emerge as a result of omitted variables or unobservable factors for which one cannot account. In the context of our analysis, this is plausible given the relatively low R-squared in the baseline model. We therefore adopt a two-stage least squares (2SLS) estimation approach to ensure results are robust to endogeneity. We instrument the average ethnic diversity at the postcode level using a measure of ethnic diversity at the state level based on 1991 (older) 
census information, which allows the instrument to operate as a lag. The logic underpinning the exclusion restriction is that historical measures of ethnic diversity should affect current levels of diversity, but should not be correlated with any unobserved factors that change contemporary attitude towards gambling. The existing literature has effectively used such lagged values to deal with endogeneity (Akay et al. 2017; Glennerster et al. 2013; Longhi 2014). In the context of our study, we use information from the 1991 Australian census to generate indices of ethnic diversity at the state level. Historic geographic patterns within a state reflect patterns of neighbourhoods (postcodes) within the state and thus, historic state level diversity should be correlated with postcode-level diversity. However, diversity from more than 2 decades prior to the collection of the HILDA gambling module will not influence gambling behaviour. The use of state-level ethnic diversity to instrument for ethnic diversity has the added advantage of using a variable from a broader geographic area to instrument diversity at a lower geographic level given that the severity of endogeneity decreases with the geographic size (Dustmann and Preston 2001).

We adopt the Lewbel (2012) 2SLS approach, which constructs internal instruments using heteroskedastic covariance restrictions as a further robustness check on our 2SLS results using external instruments. This approach has been used in the literature in the absence of external instruments or as a robustness check on findings using external instruments (Ambrey and Fleming 2014; Awaworyi Churchill and Smyth 2017; Millimet and Roy 2016). This method does not require an exclusion restriction to be met but relies on heteroskedastic covariance restrictions to achieve identification (see, Lewbel 2012 for details). We combine our external instrument (i.e., lag of ethnic diversity at the state level) with internally generated instruments to increase the predictive power of our instruments and also ensure robustness to endogeneity.

\section{Results}

Table 1 reports baseline results for the association between ethnic diversity (measured by fractionalisation) and gambling. Column 1 reports results for effects on the PGSI scores while Column 2 reports results for effects on the gambling risk categorisations. From Column 1, we find that a standard deviation increase in ethnic diversity is associated with an increase of 0.016 standard deviations in gambling behaviour measured by the PGSI score. Here, a unit change in ethnic diversity generates a $10.2 \%$ change in PGSI score. From Column 2, we find a positive coefficient on ethnic diversity, although it is statistically insignificant.

The coefficients on the included covariates reveal some noteworthy findings. For instance, male respondents are associated with higher problem gambling risk than females. Being divorced and living in urban areas are associated with higher gambling risk while higher levels of income and education are associated with lower risks of gambling harms. These findings are consistent across subsequent regressions that are reported.

Table 2 presents the 2SLS results that address endogeneity. Columns 1 and 2 report results from 2SLS regressions that use lagged diversity as the instrument. Columns 3 and 4 report findings from Lewbel 2 SLS regressions that combine the external instrument (i.e., the lag of ethnic diversity) with internally generated instruments. We find that endogeneity causes a considerable downward bias in the OLS results given that, across all panels, the 2SLS estimates are considerably higher than the OLS estimates. Specifically, from Columns 1 and 2, we find that a standard deviation increase in ethnic fractionalisation is 
Table 1 Ethnic diversity and gambling (baseline results)

\begin{tabular}{|c|c|c|}
\hline & $\begin{array}{l}(1) \\
\text { PGSI }\end{array}$ & $\begin{array}{l}\text { (2) } \\
\text { Risk status }\end{array}$ \\
\hline \multirow[t]{3}{*}{ Ethnic diversity } & $0.102^{*}$ & 0.022 \\
\hline & $(0.060)$ & $(0.018)$ \\
\hline & {$[0.016]$} & [0.011] \\
\hline \multirow[t]{2}{*}{ Male } & $0.187 * * *$ & $0.075 * * *$ \\
\hline & $(0.025)$ & $(0.008)$ \\
\hline \multirow[t]{2}{*}{ Age } & -0.000 & 0.000 \\
\hline & $(0.001)$ & $(0.000)$ \\
\hline \multirow[t]{2}{*}{ Dependants } & -0.018 & $-0.008^{*}$ \\
\hline & $(0.013)$ & $(0.004)$ \\
\hline \multirow[t]{2}{*}{ Separated } & 0.115 & 0.043 \\
\hline & $(0.080)$ & $(0.029)$ \\
\hline \multirow[t]{2}{*}{ Divorced } & $0.235 * * *$ & $0.064 * * *$ \\
\hline & $(0.079)$ & $(0.020)$ \\
\hline \multirow[t]{2}{*}{ Widowed } & -0.057 & -0.009 \\
\hline & $(0.050)$ & $(0.019)$ \\
\hline \multirow[t]{2}{*}{ Single } & 0.057 & 0.017 \\
\hline & $(0.047)$ & $(0.013)$ \\
\hline \multirow[t]{2}{*}{ Income } & $-0.060 * * *$ & $-0.023^{* * *}$ \\
\hline & $(0.020)$ & $(0.007)$ \\
\hline \multirow[t]{2}{*}{ Employed } & 0.017 & 0.005 \\
\hline & $(0.033)$ & $(0.010)$ \\
\hline \multirow[t]{2}{*}{ Postgraduate } & $-0.259 * * *$ & $-0.101 * * *$ \\
\hline & $(0.040)$ & $(0.013)$ \\
\hline \multirow[t]{2}{*}{ Graduate Diploma } & $-0.183^{* * *}$ & $-0.070^{* * *}$ \\
\hline & $(0.042)$ & $(0.013)$ \\
\hline \multirow[t]{2}{*}{ Bachelor } & $-0.150^{* * *}$ & $-0.058^{* * *}$ \\
\hline & $(0.038)$ & $(0.011)$ \\
\hline \multirow[t]{2}{*}{ Diploma } & $-0.137 * * *$ & $-0.046^{* * *}$ \\
\hline & $(0.039)$ & $(0.013)$ \\
\hline \multirow[t]{2}{*}{ Certificate } & 0.017 & 0.014 \\
\hline & $(0.038)$ & $(0.012)$ \\
\hline \multirow[t]{2}{*}{ Disability } & 0.055 & 0.016 \\
\hline & $(0.035)$ & $(0.010)$ \\
\hline \multirow[t]{2}{*}{ Australian } & -0.028 & -0.012 \\
\hline & $(0.030)$ & $(0.009)$ \\
\hline \multirow[t]{2}{*}{ Urban } & $0.088^{* *}$ & $0.042 * * *$ \\
\hline & $(0.036)$ & $(0.011)$ \\
\hline \multirow[t]{2}{*}{ Alcohol } & -0.039 & $-0.026^{* * *}$ \\
\hline & $(0.034)$ & $(0.010)$ \\
\hline \multirow[t]{2}{*}{ Constant } & $0.883^{* * *}$ & $1.332 * * *$ \\
\hline & $(0.249)$ & $(0.079)$ \\
\hline State fixed effect & Yes & Yes \\
\hline
\end{tabular}


Table 1 (continued)

\begin{tabular}{lll}
\hline & $(1)$ & $(2)$ \\
& PGSI & Risk status \\
\hline Observations & 14,061 & 14,061 \\
R-squared & 0.013 & 0.019 \\
\hline
\end{tabular}

Reference category for marital status are those married or in a de facto relationship, for educational status it is those whose highest education level is year 12 or below, and for employment status it is those unemployed or not in the labour force

Robust standard errors in parentheses. Standardised coefficients in brackets

$* * * p<0.01 ; * * p<0.05 ; * p<0.1$

Table 2 Ethnic diversity and gambling (IV results)

\begin{tabular}{lllll}
\hline Variables & $(1)$ & $(2)$ & $(3)$ & $(4)$ \\
& PGSI & Risk status & PGSI & Risk status \\
\hline Ethnic diversity & $1.246^{* * *}$ & $0.415^{* * *}$ & $0.790^{* *}$ & $0.292^{* *}$ \\
& $(0.442)$ & $(0.140)$ & $(0.352)$ & $(0.116)$ \\
& {$[0.190]$} & {$[0.204]$} & {$[0.121]$} & {$[0.144]$} \\
Controls? & Yes & Yes & Yes & Yes \\
State fixed effect & Yes & Yes & Yes & Yes \\
Observations & 14,061 & 14,061 & 14,061 & 14,061 \\
First stage & & & & \\
Instrument & $0.318^{* * * *}$ & & $0.339 * * *$ & \\
& $(0.020)$ & & $(0.021)$ & \\
F-statistics & 248.23 & & 19.92 & \\
F $p$ value & 0.0000 & & 0.0000 & \\
J statistic & - & & $15.958 / 16.080$ & \\
J $p$ value & - & & $0.3848 / 0.3767$ & \\
\hline
\end{tabular}

Columns 1 and 2 report 2SLS results using lagged diversity as instrument

Columns 3 and 4 report Lewbel 2SLS results using external and internal instruments

Robust standard errors in parentheses. Standardised coefficients in brackets

$* * * p<0.01 ; * * p<0.05 ; * p<0.1$

associated with increases of 0.190 and 0.204 standard deviations in gambling behaviour measured by the PGSI score and gambling risk, respectively. Similarly, from Columns 3 and 4, a standard deviation increase in ethnic fractionalisation is associated with a 0.121 standard deviation increase in gambling behaviour measured by the PGSI score, and 0.144 standard deviation increase in gambling behaviour measured by gambling risk. Overall, these results suggest that higher levels of ethnic diversity is associated with more risky gambling behaviour. Thus, neighbourhood ethnic diversity should be thought of as an environmental factor that can contribute to Behavioural Conditioned pathways to problem gambling. 
Table 3 Effects across risk spectrums

\begin{tabular}{lllll}
\hline & $(1)$ & $(2)$ & $(3)$ & $(4)$ \\
& No problem & Low risk & Medium risk & Problem gambler \\
\hline Ethnic diversity & 0.027 & -0.197 & $0.287 * *$ & $0.502 * * *$ \\
& $(0.153)$ & $(0.207)$ & $(0.138)$ & $(0.179)$ \\
Controls? & Yes & Yes & Yes & Yes \\
State fixed effect & Yes & Yes & Yes & Yes \\
Observations & 14,061 & 14,061 & 14,061 & 14,061 \\
\hline
\end{tabular}

Robust standard errors in parentheses

$* * * p<0.01 ; * * p<0.05 ; * p<0.1$

\section{Sensitivity Checks}

In this section, we conduct a series of tests to examine the sensitivity of our results. First, we examine the effects of ethnic diversity on the different gambling risk spectrums based on the PGSI scores. The ordinal scale of gambling risk categorises gamblers as non-problem gamblers, low-risk gamblers, moderate-risk gamblers and problem gamblers. We use a dummy variable for each risk category and run logit regressions to examine the effects of ethnic diversity on respondents in each risk category. Table 3 reports results for this exercise. Columns 1, 2, 3 and 4 report results for the effects of ethnic diversity on non-problem gamblers, low-risk gamblers, moderate-risk gamblers and problem gamblers, respectively. Although the coefficient on ethnic diversity is statistically insignificant in Columns 1 and 2 , we find that higher levels of ethnic diversity are associated with the probability of being a moderate-risk and problem gambler. The magnitude of the coefficients on ethnic diversity in Columns 3 and 4 suggests that the ethnic diversity has the strongest effect on problem gambling. Specifically, a unit increase in ethnic diversity generates a 28.7 and 50.2 percentage point changes in the probability of being a moderate-risk and problem gambler, respectively.

Second, we examine the robustness of our results to an alternative estimation method that treats the PGSI scores and risk category variables as ordinal. Consistent with the literature, our baseline results are based on OLS regressions. However, given the ordinal nature of the PGSI scores and risk category variables, one could argue in favour of ordered logits as a more appropriate estimation method. To ensure that our results are robust to the choice of estimation methods that treat gambling measures either as ordinal or cardinal, we also conduct ordered logit estimations. Results for this alternative estimation approach are reported in Panel A of Table 4. We find that ordered logit estimates reinforce the positive effect of ethnic diversity on gambling.

Third, it is likely that certain ethnic groups (e.g., minority groups) may gamble more than others, and thus it is important to control for ethnicity. In the context of our study, given that HILDA does not report information on ethnicities, we control for nationality (i.e., Australian vs non-Australian). While the coefficient on the nationality dummy shows no statistically significant difference between Australians and non-Australians with regards to PGSI scores and risk status, we further disaggregate our data into the two sub-samples (i.e., Australians and non-Australians) to examine if the impact of ethnic diversity is 
Table 4 Ethnic diversity and gambling (sensitivity checks)

\begin{tabular}{|c|c|c|}
\hline & $\begin{array}{l}\text { (1) } \\
\text { PGSI }\end{array}$ & $\begin{array}{l}\text { (2) } \\
\text { Risk status }\end{array}$ \\
\hline \multicolumn{3}{|c|}{ Panel A: ordered logit regressions } \\
\hline Ethnic diversity & $\begin{array}{l}0.268^{*} \\
(0.137)\end{array}$ & $\begin{array}{l}0.199 * * \\
(0.089)\end{array}$ \\
\hline Observations & 14,061 & 14,061 \\
\hline \multicolumn{3}{|c|}{ Panel B: Australian sub-sample } \\
\hline Ethnic diversity & $\begin{array}{l}0.200^{* * *} \\
(0.054)\end{array}$ & $\begin{array}{l}0.082 * * * \\
(0.016)\end{array}$ \\
\hline Observations & 10,110 & 10,110 \\
\hline \multicolumn{3}{|c|}{ Panel C: non-Australian sub-sample } \\
\hline Ethnic diversity & $\begin{array}{l}0.132 * * * \\
(0.038)\end{array}$ & $\begin{array}{l}0.056^{* *} \\
(0.028)\end{array}$ \\
\hline Observations & 3951 & 3951 \\
\hline \multicolumn{3}{|c|}{ Panel D: control for personality and financial risk } \\
\hline Ethnic diversity & $\begin{array}{l}0.096^{*} \\
(0.049)\end{array}$ & $\begin{array}{l}0.039 \text { ** } \\
(0.019)\end{array}$ \\
\hline Extraversion & $\begin{array}{l}0.008 \\
(0.011)\end{array}$ & $\begin{array}{l}0.007 * \\
(0.004)\end{array}$ \\
\hline Agreeableness & $\begin{array}{l}-0.013 \\
(0.018)\end{array}$ & $\begin{array}{l}0.000 \\
(0.006)\end{array}$ \\
\hline Conscientiousness & $\begin{array}{l}-0.041 * * * \\
(0.015)\end{array}$ & $\begin{array}{l}-0.013^{* *} \\
(0.005)\end{array}$ \\
\hline Emotional stability & $\begin{array}{l}-0.126^{* * *} \\
(0.016)\end{array}$ & $\begin{array}{l}-0.048^{* * * *} \\
(0.005)\end{array}$ \\
\hline Openness & $\begin{array}{l}-0.051 * * * \\
(0.014)\end{array}$ & $\begin{array}{l}-0.022^{* * * *} \\
(0.005)\end{array}$ \\
\hline Financial risk & $\begin{array}{l}0.268 * * * \\
(0.036)\end{array}$ & $\begin{array}{l}0.084 * * * \\
(0.009)\end{array}$ \\
\hline Observations & 11,275 & 11,275 \\
\hline
\end{tabular}

All regressions include the usual control variables and state fixed effects

Robust standard errors in parentheses

$* * * p<0.01 ; * * p<0.05 ; * p<0.1$

different across both sub-samples. ${ }^{1}$ Panels B and C of Table 4 report results for the Australian and non-Australian sub-samples, respectively. While the effects of ethnic diversity on gambling remains positive and significant in both sub-samples, we observe that the effects are stronger in the case of Australian sub-sample. This suggests that the impact of ethnic diversity on gambling is relatively more severe for Australians.

Fourth, we examine the sensitivity of our results to the inclusion of additional covariates in our baseline model. In one of the earliest models on the determinants of gambling,

1 We thank an anonymous reviewer for this suggestion. 
Table 5 Alternative measures of gambling
(1)

(2)

\begin{tabular}{lll} 
& Expenditure & Activities \\
\hline Ethnic diversity & $0.005^{* * *}$ & $0.110^{* * *}$ \\
& $(0.002)$ & $(0.037)$ \\
Controls? & Yes & Yes \\
State fixed effect & Yes & Yes \\
Observations & 14,061 & 14,061 \\
\hline
\end{tabular}

Robust standard errors in parentheses

$* * * p<0.01 ; * * p<0.05 ; * p<0.1$

Jacobs (1986) argues that personality traits significantly influence gambling behaviour. We take advantage of the 'Big-Five' Personality Inventory administered in waves 5, 9 and 13 of the HILDA survey to examine if the inclusion of these personality traits as additional covariates in our baseline model will influence the effect of ethnic diversity. To control for financial risk, we also take advantage of the HILDA 'financial risk' question that provides information on the amount of financial risk that respondents are willing to take with spare cash. Panel D of Table 4 reports results for regressions in which we control for the BigFive and financial risk. We find that while the coefficients on ethnic diversity remain positive, compared to the baseline results, the magnitude of the coefficient is relatively smaller. This finding could be because the impact of ethnic diversity is partly mediated by personality traits. Future research can examine this mediating role in more detail.

Next, we examine the robustness of our results to alternative ways of measuring gambling. The gambling module in the HILDA survey asked respondents about 10 gambling activities and the average monthly expenditures associated with these activities. We calculate an annual gambling expenditure variable using this information and deflate this with income to generate a variable that captures the annual gambling expenditure share of income. We also generate a second gambling variable, which is the sum of gambling activities in which respondents engage. We use these two variables as alternative measures of gambling to examine the effects of ethnic diversity. Results reported in Table 5 show that ethnic diversity is associated with an increase in (1) the number of gambling activities respondents engage in; and (2) the share of gambling expenditure to income. Specifically, we find that a unit increase in ethnic diversity is associated with a $0.5 \%$ increase in the share of gambling expenditure to income, and an $11 \%$ change in the number of gambling activities respondents engage in.

In a final check, we examine the robustness of our results to an alternative way of measuring ethnic diversity. A well-known alternative to the index of ethnic fractionalisation is the index of ethnic polarisation, which captures the conflict dimension of diversity. Thus, we examine the robustness of our results to the use of the polarisation index. Further, our main set of results are based on ethnic diversity measures where ethnicity is defined based on the country of birth of respondent's father. Here, we examine the sensitivity of our results to defining ethnicity based on: (1) respondent's country of birth, and (2) the country of birth of respondent's father. Table 6 reports results for the effects of these alternative measures of ethnic diversity. We find that the effects of ethnic diversity on gambling are not sensitive to the measure of ethnic diversity given that the positive effects of ethnic diversity on gambling are consistent albeit with varying effect sizes. 
Table 6 Alternative measures of ethnic diversity

(1)

PGSI

Risk status

Panel A: effects of ethnic polarisation

Polarisation

$0.190 * * *$

$0.076^{* * * *}$

(0.025)

(0.008)

Observations

14,061

14,061

Panel B: ethnicity defined by respondent's country of birth

Ethnic diversity

$\begin{array}{ll}0.098 * * * & 0.037 * * * \\ (0.019) & (0.006) \\ 14,061 & 14,061\end{array}$

Observations

14,061

$0.075^{* * * *}$

Ethnic diversity

$0.187 * * *$

(0.008)

Observations

14,061

All regressions include the usual control variables and state fixed effects

Robust standard errors in parentheses

$* * * p<0.01 ; * * p<0.05 ; * p<0.1$

Table 7 Effects of ethnic diversity (potential channel analysis)

\begin{tabular}{llll}
\hline Variables & $(1)$ & $(2)$ & $(3)$ \\
& Social capital & PGSI & Risk status \\
\hline ETHFRAC & $-0.219^{* * *}$ & $0.103^{*}$ & $0.022^{*}$ \\
& $(0.032)$ & $(0.060)$ & $(0.011)$ \\
Controls & {$[-0.061]$} & {$[0.018]$} & {$[0.019]$} \\
State fixed effect & Yes & Yes & Yes \\
Observations & 13,970 & Yes & Yes \\
\hline
\end{tabular}

All regressions include the usual control variables and state fixed effects

Robust standard errors in parentheses. Standardised coefficients in brackets

$* * * p<0.01 ; * * p<0.05 ; * p<0.1$

\section{Social Capital as a Channel of Influence}

As discussed in "Introduction" section, social capital is an important channel that links ethnic diversity to gambling. Thus, in this section, to inform our policy recommendations, we empirically test the potential role of social capital as a channel linking ethnic diversity to gambling. For social capital to qualify as a channel of influence, in addition to being correlated with ethnic diversity, it should also be correlated with gambling, and the inclusion of social capital as an additional covariate in the regression linking gambling to ethnic diversity should decrease the magnitude of the coefficient on ethnic diversity or render it statistically insignificant. 
Table 8 Effects of social capital (potential analysis)

\begin{tabular}{lll}
\hline Variables & $(1)$ & $(2)$ \\
& PGSI & Risk status \\
\hline ETHFRAC & 0.067 & 0.005 \\
& $(0.066)$ & $(0.020)$ \\
Social capital & {$[0.010]$} & {$[0.003]$} \\
& $-0.086^{* * *}$ & $-0.029^{* * *}$ \\
& $(0.017)$ & $(0.005)$ \\
Controls & {$[-0.048]$} & {$[-0.051]$} \\
State fixed effect & Yes & Yes \\
Observations & Yes & Yes \\
\hline
\end{tabular}

All regressions include the usual control variables and state fixed effects

Robust standard errors in parentheses. Standardised coefficients in brackets

$* * * p<0.01 ; * * p<0.05 ; * p<0.1$

Our measure of social capital is based on the six-item scale discussed in "Covariates" section. Table 7 reports results for the effects of ethnic diversity on social capital. Given that the inclusion of social capital reduces the number of observations, we also report results for the effects of ethnic diversity on gambling behaviour using the reduced number of observations to ensure the potential channel analysis is based on the same sample. Thus, Column 1 of Table 7 reports results for effects of ethnic diversity on social capital while Columns 2 and 3 report effects on PGSI and risk status, respectively. Results suggest that an increase in ethnic diversity is associated with lower social capital. Consistent with our main results (i.e., full sample), results from the reduced sample also show that ethnic diversity is positively associated with gambling behaviour.

In Table 8, we include social capital as an additional covariate in the gambling regressions. Columns 1 and 2 report results for the effects on PGSI and risk status, respectively. Consistent with expectation, we find that social capital is associated with a decline in gambling. We also find that the inclusion of social capital as an additional covariate reduces the magnitude of the coefficient on ethnic diversity in both columns as well as renders them statistically insignificant. These results, viewed together, suggest that social capital is a potential channel through which ethnic diversity influences gambling behaviour.

\section{Conclusion}

This study has sought to examine whether neighbourhood variations in ethnic diversity across Australia can explain differences in individual gambling behaviour. Based on data from the Household, Income and Labour Dynamics in Australia (HILDA) survey, we answer this question using different measures of ethnic diversity and gambling behaviours. Across different empirical specifications, we find that ethnic diversity is positively associated with gambling behaviours.

Ethnic diversity brings many benefits including increased innovation and productivity, and this is particularly true for a diverse society such as Australia. Our findings, therefore, 
point to the need for policies that mitigate the negative effects of diversity on social capital. Indeed, as local communities become more diverse, individuals are presented with increased opportunities to interact with people of different ethnic groups with different cultures, practices and beliefs. This should be viewed as an opportunity to facilitate intergroup cooperation that builds social cohesion rather than discrimination. As a multicultural society, it is important to foster greater tolerance through relevant education policies that help individuals embrace each other's differences. This forges stronger bonds that discourage social exclusion, which is likely to provoke or nurture gambling behaviour. Our results also suggest the need for multicultural gambling education in highly diverse communities.

The results suggest that ethnic diversity is an important factor in understanding Behavioural Conditioned pathways to problem gambling and thus adds new knowledge to the Blaszczynski and Nower (2002) pathways model of problem gambling. We also contribute to the body of literature that examines the role of environmental factors as determinants for gambling behaviours. This research is important as there are clear regulation and policy actions that can be taken to address local area factors and help reduce the number of problem gamblers in our communities.

\section{Compliance with Ethical Standards}

Conflict of interest The authors declare that they have no conflict of interest.

Ethical Approval This article does not contain any studies with human participants or animals performed by any of the authors.

\section{Appendix}

See Tables 9, 10 and 11. 


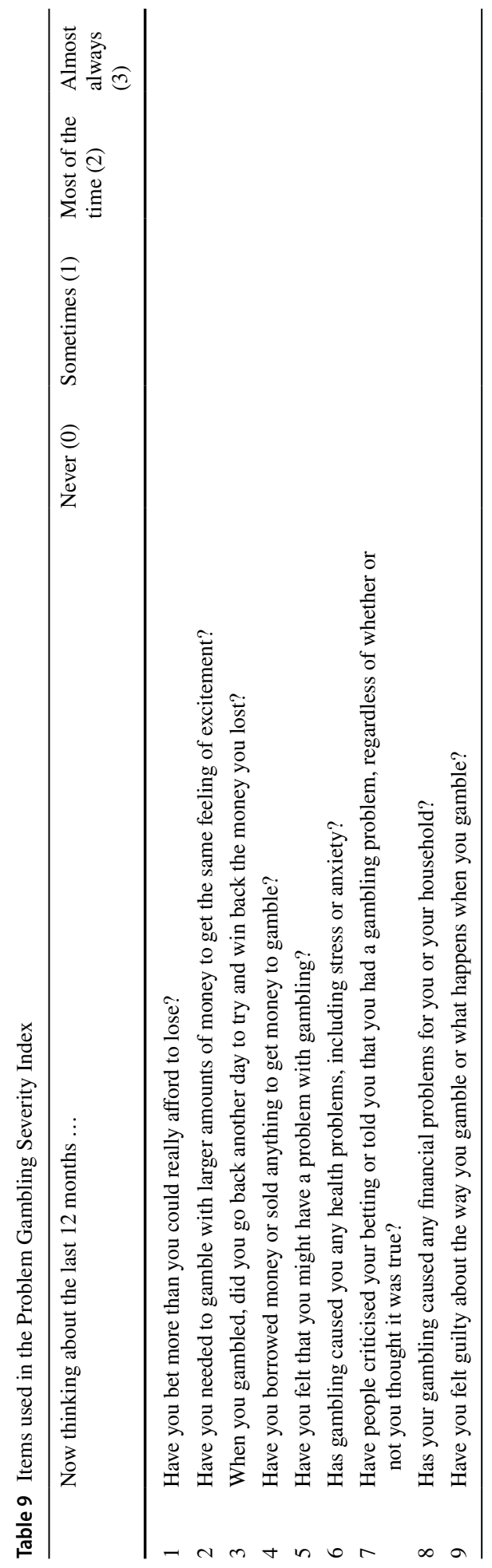




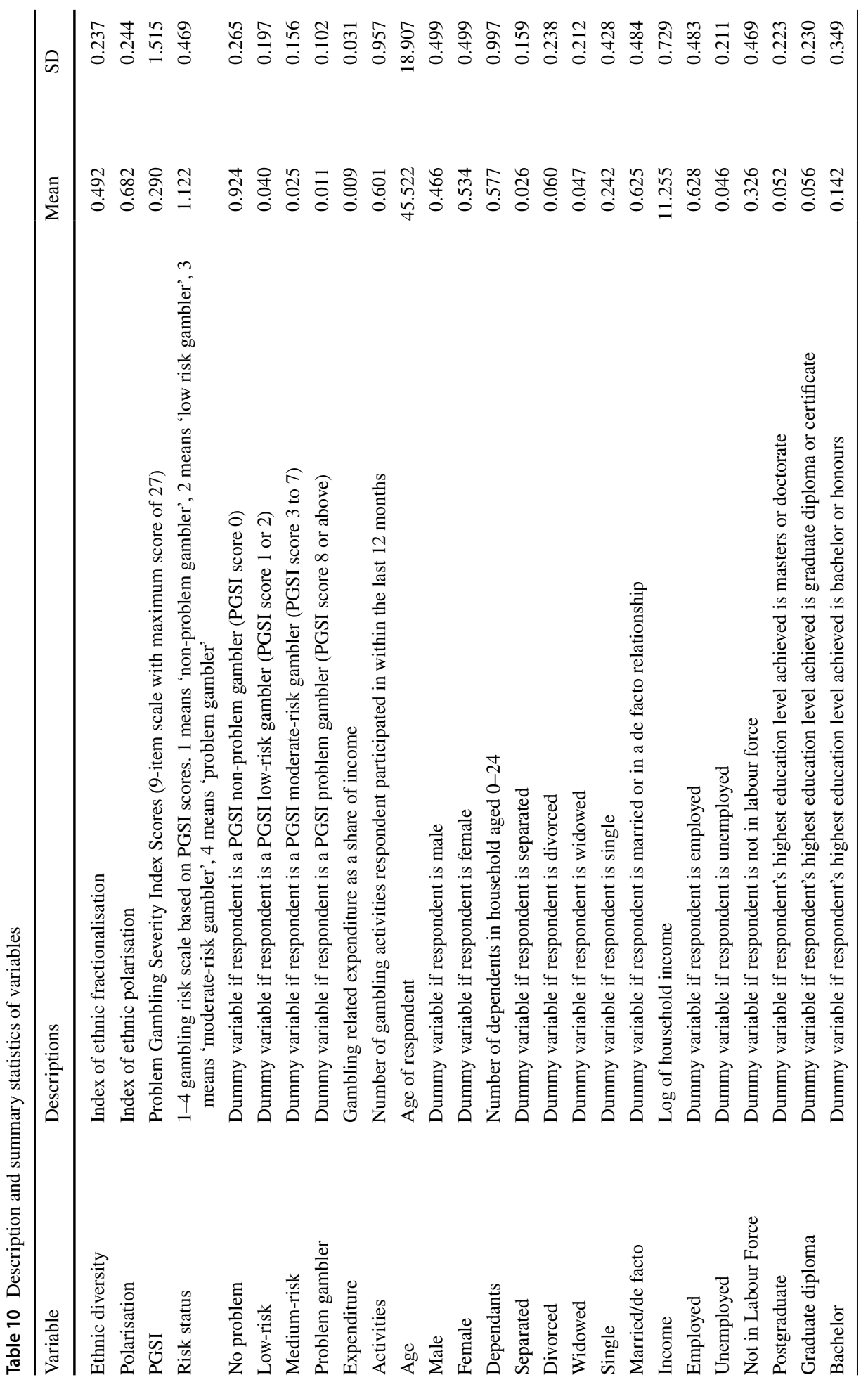




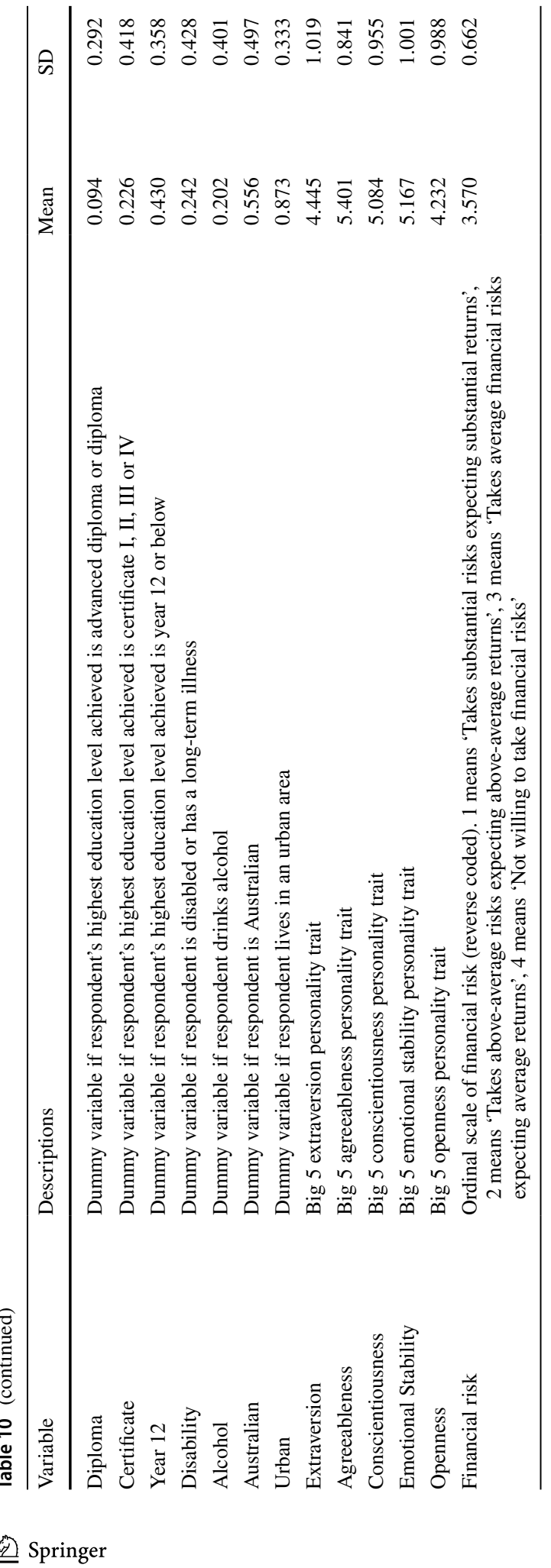




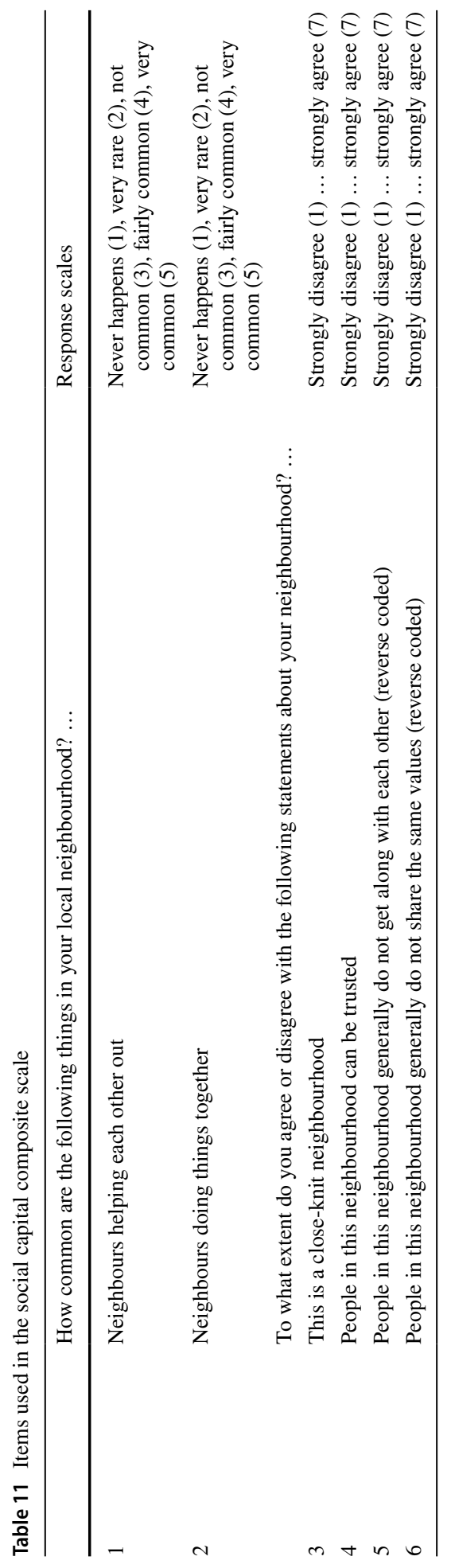




\section{References}

Akay, A., Constant, A., Giulietti, C., \& Guzi, M. (2017). Ethnic diversity and well-being. Journal of Population Economics, 30(1), 265-306.

Ambrey, C., \& Fleming, C. (2014). Public greenspace and life satisfaction in urban Australia. Urban Studies, 51(6), 1290-1321.

APA. (1980). Diagnostic and statistical manual of mental disorders (3rd edition) (DSM-III). Washington, DC: American Psychiatric Association.

APA. (2013). Diagnostic and statistical manual of mental disorders (5th edition) (DSM-V). Washington, DC: American Psychiatric Association.

Australian Bureau of Statistics. (2017). Census of population and housing 2016. Cat No. 2024.0. Canberra: Australian Bureau of Statistics.

Awaworyi Churchill, S. (2017). Fractionalization, entrepreneurship, and the institutional environment for entrepreneurship. Small Business Economics, 48(3), 577-597. https://doi.org/10.1007/s1118 7-016-9796-8.

Awaworyi Churchill, S., \& Farrell, L. (2018). The impact of gambling on depression: New evidence from England and Scotland. Economic Modelling, 68, 475-483. https://doi.org/10.1016/j.econm od.2017.08.021.

Awaworyi Churchill, S., \& Smyth, R. (2017). Ethnic diversity and poverty. World Development, 95, 285302. https://doi.org/10.1016/j.worlddev.2017.02.032.

Baron, E., \& Dickerson, M. (1999). Alcohol consumption and self-control of gambling behaviour. Journal of Gambling Studies, 15(1), 3-15. https://doi.org/10.1023/a:1023057027992.

Blaszczynski, A., \& Nower, L. (2002). A pathways model of problem and pathological gambling. Addiction, 97(5), 487-499.

Brown, D. J., Kaldenberg, D. O., \& Browne, B. A. (1992). Socioeconomic-status and playing the lotteries. Sociology and Social Research, 76(3), 161-167.

Bursztyn, L., Ederer, F., Ferman, B., \& Yuchtman, N. (2014). Understanding mechanisms underlying peer effects: Evidence from a field experiment on financial decisions. Econometrica, 82(4), 1273-1301.

Calado, F., \& Griffiths, M. D. (2016). Problem gambling worldwide: An update and systematic review of empirical research (2000-2015). Journal of Behavioral Addictions, 5(4), 592-613.

Chhabra, D. (2007). Ethnicity and marginality effects on casino gambling behavior. Journal of Vacation Marketing, 13(3), 221-238.

Clotfelter, C., \& Cook, P. J. (1999). State lotteries at the turn of the century: Report to the National Gambling Impact Study Commission. Washington, DC: National Gambling Impact Study Commission.

Currie, S. R., Hodgins, D. C., \& Casey, D. M. (2013). Validity of the problem gambling severity index interpretive categories. Journal of Gambling Studies, 29(2), 311-327.

Currie, S. R., Hodgins, D. C., Wang, J., El-Guebaly, N., Wynne, H., \& Chen, S. (2006). Risk of harm among gamblers in the general population as a function of level of participation in gambling activities. Addiction, 101(4), 570-580.

Davidson, T., Rodgers, B., Markham, F., \& Taylor-Rodgers, E. (2016). Gambling expenditure in the ACT (2014): By level of problem gambling, type of activity, and socioeconomic and demographic characteristics. Canberra: Australian Capital Territory Gambling and Racing Commission.

Delfabbro, P., \& Thrupp, L. (2003). The social determinants of youth gambling in South Australian adolescents. Journal of Adolescence, 26(3), 313-330. https://doi.org/10.1016/S0140-1971(03)00013-7.

Dincer, O. C. (2011). Ethnic diversity and trust. Contemporary Economic Policy, 29(2), 284-293.

Dinesen, P. T., \& Sønderskov, K. M. (2015). Ethnic diversity and social trust: Evidence from the microcontext. American Sociological Review, 80(3), 550-573.

Dowling, N. A., Youssef, G., Jackson, A. C., Pennay, D., Francis, K. L., Pennay, A., et al. (2016). National estimates of Australian gambling prevalence: Findings from a dual-frame omnibus survey. Addiction, 111(3), 420-435.

Dustmann, C., \& Preston, I. (2001). Attitudes to ethnic minorities, ethnic context and location decisions. The Economic Journal, 111(470), 353-373.

Easterly, W., \& Levine, R. (1997). Africa's growth tragedy: Policies and ethnic divisions. The Quarterly Journal of Economics, 112(4), 1203-1250.

Ferris, J. A., \& Wynne, H. J. (2001). The Canadian problem gambling index. Ottawa, ON: Canadian Centre on Substance Abuse.

Gainsbury, S. M., Russell, A., Hing, N., Wood, R., Lubman, D. I., \& Blaszczynski, A. (2014). The prevalence and determinants of problem gambling in Australia: Assessing the impact of interactive gambling and new technologies. Psychology of Addictive Behaviors, 28(3), 769-779. https://doi. org/10.1037/a0036207. 
Glennerster, R., Miguel, E., \& Rothenberg, A. D. (2013). Collective action in diverse Sierra Leone communities. The Economic Journal, 123(568), 285-316.

Greenberg, J. H. (1956). The measurement of linguistic diversity. Language, 32(1), 109-115.

Griffiths, M., \& Barnes, A. (2008). Internet gambling: An online empirical study among student gamblers. International Journal of Mental Health and Addiction, 6(2), 194-204.

Hasin, D. S., O’Brien, C. P., Auriacombe, M., Borges, G., Bucholz, K., Budney, A., et al. (2013). DSM-5 criteria for substance use disorders: Recommendations and rationale. American Journal of Psychiatry, $170(8), 834-851$.

Hewlett, S. A., Marshall, M., \& Sherbin, L. (2013). How diversity can drive innovation. Harvard Business Review, 91(12), 30.

Holtgraves, T. (2008). Evaluating the Problem Gambling Severity Index. Journal of Gambling Studies, 25(1), 105. https://doi.org/10.1007/s10899-008-9107-7.

Jacobs, D. F. (1986). A general theory of addictions: A new theoretical model. Journal of Gambling Behavior, 2(1), 15-31. https://doi.org/10.1007/bf01019931.

Korman, L. M., Collins, J., Dutton, D., Dhayananthan, B., Littman-Sharp, N., \& Skinner, W. (2008). Problem gambling and intimate partner violence. Journal of Gambling Studies, 24(1), 13-23. https ://doi.org/10.1007/s10899-007-9077-1.

Korn, D., Gibbins, R., \& Azmier, J. (2003). Framing public policy towards a public health paradigm for gambling. Journal of Gambling Studies, 19(2), 235-256. https://doi.org/10.1023/a:1023685416816.

Langham, E., Thorne, H., Browne, M., Donaldson, P., Rose, J., \& Rockloff, M. (2016). Understanding gambling related harm: A proposed definition, conceptual framework, and taxonomy of harms. BMC Public Health, 16(1), 80. https://doi.org/10.1186/s12889-016-2747-0.

Layton, A., \& Worthington, A. (1999). The impact of socio-economic factors on gambling expenditure. International Journal of Social Economics, 26(1/2/3), 430-440. https://doi.org/10.1108/03068 299910230035.

Leigh, A. (2006). Trust, inequality and ethnic heterogeneity. Economic Record, 82(258), 268-280.

Levens, S., Dyer, A.-M., Zubritsky, C., Knott, K., \& Oslin, D. W. (2005). Gambling among older, primary-care patients: An important public health concern. The American Journal of Geriatric Psychiatry, 13(1), 69-76. https://doi.org/10.1097/00019442-200501000-00010.

Lewbel, A. (2012). Using heteroscedasticity to identify and estimate mismeasured and endogenous regressor models. Journal of Business \& Economic Statistics, 30(1), 67-80. https://doi. org/10.1080/07350015.2012.643126.

Longhi, S. (2014). Cultural diversity and subjective well-being. IZA Journal of Migration, 3(1), 13.

Marshall, D. C. (2005). The gambling environment and gambler behaviour: Evidence from RichmondTweed, Australia. International Gambling Studies, 5(1), 63-83.

McQuade, A., \& Gill, P. (2012). The role of loneliness and self-control in predicting problem gambling behaviour. Gambling Research, 24(1), 18-30.

Millimet, D. L., \& Roy, J. (2016). Empirical tests of the pollution haven hypothesis when environmental regulation is endogenous. Journal of Applied Econometrics, 31(4), 652-677. https://doi. org/10.1002/jae.2451.

Montalvo, J. G., \& Reynal-Querol, M. (2005). Ethnic polarization, potential conflict, and civil wars. American Economic Review, 95(3), 796-816.

Oei, T. P., \& Raylu, N. (2010). Gambling behaviours and motivations: A cross-cultural study of Chinese and Caucasians in Australia. International Journal of Social Psychiatry, 56(1), 23-34.

Orford, J., Wardle, H., Griffiths, M., Sproston, K., \& Erens, B. (2010). PGSI and DSM-IV in the 2007 British gambling prevalence survey: Reliability, item response, factor structure and inter-scale agreement. International Gambling Studies, 10(1), 31-44.

Ottaviano, G. I., \& Peri, G. (2006). The economic value of cultural diversity: Evidence from US cities. Journal of Economic Geography, 6(1), 9-44.

Productivity Commission. (2010). Gambling, report no. 50, Canberra.

Queensland Government Statistician's Office. (2018). Australian gambling statistics (34th ed.). Brisbane: Queensland Treasury.

Raisamo, S. U., Mäkelä, P., Salonen, A. H., \& Lintonen, T. P. (2014). The extent and distribution of gambling harm in Finland as assessed by the Problem Gambling Severity Index. The European Journal of Public Health, 25(4), 716-722.

Raylu, N., \& Oei, T. P. (2004). Role of culture in gambling and problem gambling. Clinical Psychology Review, 23(8), 1087-1114. https://doi.org/10.1016/j.cpr.2003.09.005.

Rogers, P. (1998). The cognitive psychology of lottery gambling: A theoretical review. Journal of Gambling Studies, 14(2), 111-134. 
Rogers, P., \& Webley, P. (2001). "It could be us!”: Cognitive and social psychological factors in UK National Lottery play. Applied Psychology, 50(1), 181-199.

Savolainen, I., Sirola, A., Kaakinen, M., \& Oksanen, A. (2018). Peer group identification as determinant of youth behavior and the role of perceived social support in problem gambling. Journal of Gambling Studies. https://doi.org/10.1007/s10899-018-9813-8.

Shaffer, H. J., \& Korn, D. A. (2002). Gambling and related mental disorders: A public health analysis. Annual Review of Public Health, 23(1), 171-212. https://doi.org/10.1146/annurev.publhealth .23.100901.140532.

Splevins, K., Mireskandari, S., Clayton, K., \& Blaszczynski, A. (2010). Prevalence of adolescent problem gambling, related harms and help-seeking behaviours among an Australian population. Journal of Gambling Studies, 26(2), 189-204.

Stevens, M., Thoss, M., \& Barnes, T. (2015). Northern Territory gambling prevalence and wellbeing survey report. Darwin: Charles Darwin University.

Stucki, S., \& Rihs-Middel, M. (2007). Prevalence of adult problem and pathological gambling between 2000 and 2005: An update. Journal of Gambling Studies, 23(3), 245-257. https://doi.org/10.1007/ s10899-006-9031-7.

Subramaniam, M., Wang, P., Soh, P., Vaingankar, J. A., Chong, S. A., Browning, C. J., et al. (2015). Prevalence and determinants of gambling disorder among older adults: A systematic review. Addictive Behaviors, 41, 199-209.

Tan, A. K. G., Yen, S. T., Nayga, J., \& Rodolfo, M. (2010). Socio-demographic determinants of gambling participation and expenditures: Evidence from Malaysia. International Journal of Consumer Studies, 34(3), 316-325. https://doi.org/10.1111/j.1470-6431.2009.00856.x.

Thomas, A. C., Allen, F. C., \& Phillips, J. (2009). Electronic gaming machine gambling: Measuring motivation. Journal of Gambling Studies, 25(3), 343-355.

Trax, M., Brunow, S., \& Suedekum, J. (2015). Cultural diversity and plant-level productivity. Regional Science and Urban Economics, 53, 85-96.

van der Maas, M. (2016). Problem gambling, anxiety and poverty: An examination of the relationship between poor mental health and gambling problems across socio-economic status. International Gambling Studies, 16(2), 281-295. https://doi.org/10.1080/14459795.2016.1172651.

Volberg, R. A. (1996). Prevalence studies of problem gambling in the United States. Journal of Gambling Studies, 12, 111-128.

Volberg, R. A., Hedberg, E. C., \& Moore, T. L. (2008). Oregon youth and their parents: Gambling and problem gambling prevalence and attitudes. Salem, Oregon: Oregon Department of Human Services.

Walker, G. J., Courneya, K. S., \& Deng, J. (2006). Ethnicity, gender, and the theory of planned behavior: The case of playing the lottery. Journal of Leisure Research, 38(2), 224-248. https://doi.org/10.1080/00222 216.2006.11950077.

Wardle, H., Keily, R., Astbury, G., \& Reith, G. (2014). 'Risky places?': Mapping gambling machine density and socio-economic deprivation. Journal of Gambling Studies, 30(1), 201-212.

Watson, N., \& Wooden, M. P. (2012). The HILDA survey: A case study in the design and development of a successful household panel survey. Longitudinal and Life Course Studies, 3(3), 369-381.

Publisher's Note Springer Nature remains neutral with regard to jurisdictional claims in published maps and institutional affiliations. 